\title{
Analysis of risks arising in the implementation of BIM - technologies in construction organizations
}

\author{
Nikolay Garyaev ${ }^{*}$ \\ Moscow State University of Civil Engineering, Yaroslavskoe shosse, 26, Moscow, 129337, Russia
}

\begin{abstract}
This paper examines the risks associated with the process of implementing BIM in the organization, as well as the risks associated with the actual use of BIM - technologies. In the first case, risks act as threats, and in the second - in the role of opportunities. Their identification consists in the search for correlation dependence, analysis and use of these studies as a justification for the need to switch to BIM technology. The research methods are based on the analysis of Russian and foreign sources to explain and identify key risks and problems associated with the use of BIM technologies in the construction sector. Based on the conducted studies, a method of risk assessment that can be encountered in the transition to BIM - technologies is proposed.
\end{abstract}

\section{Introduction}

Information modeling technologies (BIM-technologies) undergo a complex process of implementation in the construction industry in Russia. In developed countries, BIM has been widely disseminated and supported at the national level, operating under unified national standards, for example in Finland, the United States of America and Singapore. Unconditional leader in the application of BIM-technologies is the United Kingdom, in this country there has already been a complete reorganization of the principles of the work of design and construction organizations. In Russia, and also, in some countries of Southern and Eastern Europe, interest in BIM technologies is just beginning to develop. An important role in the introduction of new technologies belongs to the state, since it is the government that creates the environment for BIM implementation (especially in the form of standardization). The experience of foreign colleagues shows that the introduction of BIM in construction and asset management brings substantial financial savings.

This article analyzes the risks associated with the implementation of BIM-technologies.

\footnotetext{
* Corresponding author: garyaev@mail.ru
} 


\section{Overview of BIM - technologies}

$\mathrm{BIM}$ is a process of managing information about a building object that allows users to collect object-oriented multidimensional parametric models (BIM-models) and on their basis to solve specific tasks throughout the life cycle of a building object.

$\mathrm{BIM}$, on the one hand, is viewed as a project management tool, and on the other hand as a methodological basis for design. Under the tool is understood not only a set of software and hardware or computers, but also tools for visualization, GPS navigation and RFID accounting. The methodological group is much more complicated. It defines methodologies, procedures, standards for data exchange, assignment of roles and responsibilities among participants. It is this group that determines the success of the introduction of BIM technologies in construction companies.

To date, the concept of BIM is in demand in many countries. Active development of standards and regulations, including international ones, is being carried out. But Russia at the moment is only on the verge of introducing BIM technologies.

Object-oriented parametric modeling has already been used in various areas. For example, in the field of mechanical engineering or electronics. But it took much more time for BIM-technologies to be used in construction. First of all, this is due to the fact that any construction project is complex and unique, requiring enormous amounts of work and resources. In this regard, the process of implementing BIM in building design is very complicated.

The experience of foreign colleagues demonstrates that the implementation of BIM technologies in Russia can significantly facilitate and simplify the process of work on the project, as information modeling technologies are designed to provide new collaborative processes through the organization of common access to the project, including: visual visualization of $3 \mathrm{D}$, interdisciplinary coordination, parallel work and so on.

Currently, BIM is an up-to-date technology that offers more efficient and better construction projects aimed at reducing costs and monitoring throughout the life cycle: from the project development stage, to demolition or reconstruction. BIM can be used at every design stage. The list of uses is extensive and includes, for example, modeling current conditions, budgeting and time planning. Other uses of BIM are project overview, leasing, document certification and standardization, project development, 3D coordination and planning, as well as operational planning, digital assembly, model analysis of construction, facility management, maintenance, reconstruction plans. In each of these areas there are risks, and all project risks must be manageable.

\section{Management of risks}

In accordance with international standards ISO 31000: 2009, risk is "the choice of uncertainty regarding the objectives." Each part of the project cycle is subject to risks that must be predicted to remain under control and help to optimize the achievement of the objectives.

Risk management is a set of activities aimed at analyzing, identifying, assessing and monitoring risks. Risks are defined as the possibility of accidental occurrence of undesirable events. The situation of risk is the qualitative or quantitative determination of the degree of probability of the outcome of an event. The risk can be considered from two positions. On the one hand, the risk is the probability that an event will occur, on the other hand it is the consequences of risk.

Another important concept related to risk management is the notion of a risk owner. The risk owner is a person or organizational unit that has authority and is responsible for managing the risk. A source of risk refers to a system object - an element that, individually 
or in combination, has its own potential to cause risk. The risk recipient is a subject of the system, which will suffer from the consequences of risk as a result of the implementation of the risk scenario. Risks, too, can have both external and internal character. External describes the relationship between the organization and the environment, while internal risk can be associated with relationships within the organization.

In a simple language, risk is usually understood as something negative. In science, risk is subjective and neutral in nature. Any event that occurred can be understood as positive or negative, based on the type of risk. Benefits for one, can harm another. This feature of risk is called polarity. As a consequence, there is a negative and positive understanding of events and risks, which are called chances and dangers (for events), as well as opportunities and threats (for risks). These terms are often used interchangeably, for example, the danger is often used as a reference to an event. The emergence of risk can bring both benefit and harm, or both. Risks need to be considered not only as threats, but also as opportunities.

\section{Risks in the implementation of BIM}

When implementing BIM - technologies in a construction company, you can face some serious threats. The risk assessment at the construction stage is included in the main stages of the business plan development. The price of incorrect accounting for this risk component is the underfunding of the investment project. The use of information modeling technologies entails both the emergence of new opportunities and the emergence of new threats.

Abroad, where BIM-technologies are introduced not for the first year, a lot of articles on the topic of risks were used when using BIM. The work often mentions the risks associated with BIM when applying specific project planning programs.

Also, the risks associated with specific BIM tools are often mentioned. For example, collision detection or security planning tools for the operation of buildings and structures. In other articles, BIM is seen as a source of risk. First of all, we are talking about the risks associated with legal and investment problems.

Analysis of studies on the effectiveness of the use of BIM-technology shows that the use of BIM-technology contributes to the economic efficiency of construction projects. The authors of the work see the reasons that prevent the introduction of information modeling technologies in Russian construction companies in that there is currently insufficient regulatory framework in the country, there is no single state standard and regulations for the implementation of construction projects using BIM technologies, and there is a shortage of qualified personnel. This analysis was conducted using open interviews with representatives of investment and construction organizations, as well as by analyzing the documents presented in various media outlets and presentations by representatives of organizations at conferences and other events.

The authors $[4,5,6,7,10]$ in their works analyze the possibility of introducing and developing BIM-technologies, in various areas of daily life, while paying great attention to issues of risk in the implementation of investment and construction projects.

Considering the authors $[1,2,8,9,10]$, which already offer at the design stage to evaluate all possible risks, while touching on the topic of safe operation, it can be concluded that the use of BIM-technology in the planning of construction processes at the stage of project development allows conduct an assessment of risks arising from direct production. This allows us to evaluate typical processes throughout the implementation phase of the project and build a clearer logistics for them. 


\section{Implementation of BIM}

The emergence of new technologies entails the emergence of new problems. Such problems were encountered when trying to implement BIM in Russia. First of all, they are connected with the lack of a regulatory framework on this issue, with the need to develop standards and the lack of qualified personnel [5]. At present, in the Russian Federation, the introduction of BIM-technologies is still at the initial stage. However, the need to quickly master the technologies of information modeling has already been recognized by many participants of the investment and construction industry and recognized at the state level. It's not just about the interaction between the tools used, but also about the introduction of new workflows. The technology and quality of BIM tools were a problem ten years ago. Today, the actual topic is the successful implementation of BIM in common use, which means the effective use of BIM-technologies at the level of the project team.

The process of implementing BIM, according to foreign experience, it is necessary to begin with the standardization of processes. Once national standards and technical regulations are developed at the national level, it is possible to embark on the process of introducing new technologies. According to the analysis of the introduction of BIM technologies into foreign construction companies, the whole process should be divided into 2 main stages.

The first stage is the whole process of implementing BIM, divided into phases. The second stage is the post-implementation phase. Two of these stages are connected and may overlap. They form a cycle, that is, after the post-implementation phase, implementation processes can follow. In addition, information collected during the pilot implementation projects can be used as a base for other projects. In the post-implementation phase, the BIM model can be used throughout the entire lifecycle of the object. These advantages are difficult to classify, because they can intersect and are often interconnected. As a rule, the advantages are a reduction in the cost of the building site throughout the life cycle, higher quality, more efficient design, construction and maintenance solutions. This leads to faster construction, improved safety throughout the entire life cycle, better risk management with fewer errors and higher performance.

When using BIM-technologies also, there are risks that can adversely affect the progress of the construction process, if they are not managed properly. Among the most important factors can be attributed the correct alignment of all components during the development of the project, to reduce the number of collisions (especially at the design stage) and the proper organization of teamwork on the project.

Due to the long-term nature of construction projects, the process of introducing new technologies in the construction sector is very difficult. It is necessary to prepare a legislative, legal and regulatory framework in terms of issuing standards, readiness for capital expenditures for implementation, not only for the purchase of equipment and software, but also for staff development.

According to the source $[10,8]$, several pilot projects with the use of new technologies and about three years are usually required to evaluate the results of their implementation. When implementing any new process, which is applicable to the implementation of BIM, quality control and risk management are considered as the most important recommendations.

\section{Risk Management BIM}

When introducing new technologies, a construction company faces new opportunities and threats. These threats can harm the recipients of risk. Damage can be expressed both in the form of material costs, and in the form of the need to eliminate the consequences. However, 
the use of BIM has many opportunities and leads to various advantages (for example, competitive advantage, reducing threats, reducing costs, and so on).

Now it is already clear that BIM-technologies allow minimizing, and in some cases, reducing the risks associated with design errors and errors that arise during construction. The introduction of new innovative technologies has an impact on both external and internal risks of the company [10]. These risks can arise both during the implementation phase and at the stage of using the new technology. In a market where BIM is not yet common, companies are exposed to innovative risks that need to be controlled. To successfully manage innovative risks, it is important to build the right business strategy for using BIM.

The use of BIM-technologies positively influences the management of risks, helps mitigate threats and open up new opportunities. At the same time, the introduction of BIM itself is associated with new risks.

It is recommended to apply a proactive approach to risk management, which, based on the separation of the BIM implementation process into stages, assesses the impact of each stage on the formation of final risks, understands the consequences and determines the stages that need to be adjusted.

When analyzing the implementation of BIM, two empirical rules must be observed. First, the total cost of implementation should be lower than the profit received. Secondly, the cost of implementation should be acceptable.

One of the problems is the calculation of future costs and profits. This problem has uncertainty, which must be addressed. One way to manage uncertainty is to correctly define and describe the relationship between risks at the implementation and post-implementation stages in order to identify correlation dependencies.

In this case, this information has two main uses. First, for risk management. Second, to make management decisions in the implementation of BIM. The correlation between risks acts as an interdependence between random variables, and can not only help understand the risks involved, but also helps identify key factors in implementing BIM to optimize the entire process.

Correlation dependence is usually represented by a special coefficient or function. The most common factor is the Pearson coefficient, which is determined from the interval "-1" for anticorrelation, to " 1 " for the total linear correlation, and " 0 " means no linear correlation. In the case of more complex correlation, it is necessary to use non-linear functions. Correlation can be positive (when there is a direct proportional relationship between the two risks: one risk has a positive effect, another risk is a negative one.) Similarly, in the presence of a backward proportional relationship, this is called a negative correlation of risk (one risk adversely affects the other risk and Sometimes the correlation of risk can be one-sided, which means that the relationship is valid only from one risk to another.

\section{Conclusions}

This article considers the topic of risks that can be encountered in the process of implementing BIM - technologies. The described principle can be applied to different implementation processes, when switching to such large-scale technologies as BIM, following this principle is especially important. This is due to the fact that at the moment there is insufficient information about the risks in the implementation of BIM, since this technology is still new and not tested in Russia, it is not completely clear what risks can be encountered and what ways to minimize them exist. Unfortunately, the mentioned correlations vary depending on the differences in the project. Therefore, further studies aimed at specific pilot projects are needed to describe the correct model for the correlation 
of risks. Such models can later be used to support the implementation of BIM, analysis and correlation of risks.

This work was financially supported by Ministry of Science and Higher Education of the Russian Federation (\#NSh-3492.2018.8).

\section{References}

1. Adamtsevich A., Ginzburg A., Shilova L., Shilov L. Implementation of BIMtechnologies in Russian construction industry according to the international experience / Journal of Applied Engineering Science, 14 (4), p. 457-460 (2016).

2. Afanas'ev A., Ginzburg A., Kozhevnikova S., Stepanov V. Organization of concrete works on the bases of the information system of tracking / Proceedings of the 19th International Scientific Conference "Energy Management of Municipal Transportation Facilities and Transport EMMFT 2017”. Khabarovsk, Russia 10-13 April 2017. Advances in Intelligent Systems and Computing, vol 692. Springer, Cham. https://doi.org/10.1007/978-3-319-70987-1_126.

3. Bolotova A., Ginzburg A., Dolganov A., Vedyakov I., Vaynshteyn M. Organizationaltechnological reliability of monolithic construction / Proceedings of the 19th International Scientific Conference "Energy Management of Municipal Transportation Facilities and Transport EMMFT 2017”. Khabarovsk, Russia 10-13 April 2017. Advances in Intelligent Systems and Computing, vol 692. Springer, Cham. https://doi.org/10.1007/978-3-319-70987-1_124.

4. Garyaev N.A. Design and analysis of information model hotel complex. MATEC Web of Conferences 2016. C. 06007.

5. Garyaev N.A. Geographically distributed learning network construction industry. Computing in Civil and Building Engineering Proceedings 2014 International Conference. 2014. C. 1578-1585.

6. Garyaev P.N. Computer-aided zoning and urban planning. Computing in Civil and Building Engineering Proceedings 2014 International Conference. 2014. C. 1618-1625.

7. Garyaeva V.V., Garyaev N.A. Integrated assessment of the technical condition of the housing projects on the basis of computer technology. Computing in Civil and Building Engineering Proceedings 2014 International Conference. 2014. C. 1336-1343.

8. Kagan P. The engineering communication networks - the issues of use of standards for the information representation in design, construction and operation, Procedia Engineering 25th. , "25th Polish - Russian - Slovak Seminar Theoretical Foundation of Civil Engineering", pp. 261-265. (2016)

9. Kagan P.B., Barabanova T.A., The Formal Language for Describing Technological Processes in Construction, Computing in Civil and Building Engineering - pp. 22322237 ( 2014)

10. Ryzhkova A., Ginzburg A., Accounting "pure" risks in early stage of investment in construction projects with energy efficient technologies in use / Applied Mechanics and Materials Vols. 672-674 (2014), Trans Tech Publications, Switzerland, 2014, -pp. 2221-2224. 